\title{
Arbor
}

\section{Inteligencia y planificación en el Ejército. Una aproximación prospectiva}

Antonio Arregui Asta

Arbor CLXV, 651 (Marzo 2000), 445-474 pp.

La Planificación en los Ejércitos abarca múltiples facetas, desde la determinación de su entidad, composición y misiones, al establecimiento de los posibles escenarios de intervención. En esta planificación han de tenerse en cuenta no sólo datos conocidos o predeterminados, sino también factores inciertos referidos especialmente a los riesgos o amenazas que presumiblemente tendrán que afrontar o evitar. En este artículo se consideran los parámetros conocidos y se pasa a analizar qué es, cómo se elabora y qué productos puede proporcionar la Inteligencia Militar para apoyar el proceso de planificación. Se estudian sus analogías y diferencias con algunas técnicas de exploración del futuro, estableciéndose una relación de complementaridad entre la Inteligencia y la Prospectiva. Finalmente se contempla la previsible evolución del Sistema de Inteligencia Militar al que se le augura un papel más relevante, si cabe, en el seno de las Fuerzas Terrestres del futuro.

\section{Reflexiones sobre las Fuerzas Armadas}

La Ley de Régimen del Personal ${ }^{1}$, recientemente promulgada, establece un nuevo modelo de Fuerzas Armadas basado en unos Ejércitos constituidos en su totalidad por soldados profesionales. Estos Ejércitos, convenientemente remozados, han de ser el instrumento armado del 
futuro al servicio de la Defensa Nacional, dispuesto siempre a cumplir las misiones que nuestra Carta Magna les encomienda.

La simple lectura de la exposición de motivos de la Ley, que aporta un amplio repertorio de razonadas justificaciones, da pie a reflexionar sobre el presente y el porvenir de nuestras Fuerzas Armadas, en general y sobre el Ejército de Tierra, en particular. Expresa conceptos - que vienen a ser declaraciones de intenciones en unos casos o afirmaciones basadas en la realidad actual en otros- tales como «la potenciación de las organizaciones colectivas de seguridad y defensa", la consideración de «nuevas misiones añadidas a las tradicionales de autodefensa», la búsqueda de nuevas soluciones «compaginando el número de efectivos con su calidad y preparación", la constatación de las implicaciones de la «revolución tecnológica» en la que nos encontramos inmersos, la «necesidad de contar con unas fuerzas armadas con un elevado nivel de preparación y un alto grado de disponibilidad», la voluntad de disponer de un nuevo modelo de fuerzas armadas capaces de cumplir eficazmente con sus misiones y de constituir una adecuado instrumento de disuasión y de política exterior en el nuevo panorama estratégico del siglo XXI», etc.

Todas estas ideas facilitan un marco de referencia que permite orientar a nuestras Fuerzas Armadas hacia el futuro. En este contexto, será preciso ir acomodando los Ejércitos actuales a la situación, siempre cambiante, para, de forma racional y equilibrada, dotarlos y adiestrarlos individual y conjuntamente de modo que en todo momento estén en disposición de ser utilizados como herramientas de ejecución de la estrategia militar nacional, teniendo previsto su empleo en cuantas contingencias puedan requerirlo. Sus fundamentos doctrinales de empleo, su personal, su material y apoyo logístico y el propio concepto de su actuación conjunta al servicio de la Defensa Nacional han de ser objeto de permanente análisis para que puedan ajustarse a la acelerada evolución en todos los campos, atentos no sólo a los actuales riesgos y a su variación, al compás de los tiempos, sino también a la temprana detección de nuevas circunstancias que puedan amenazar militarmente nuestros intereses nacionales. Este proceso evolutivo que conduce hacia el futuro se manifiesta tanto más incierto cuanto más nos adentramos en el tiempo o más elevado es el nivel de las decisiones a adoptar.

Los Ejércitos, organismos vitales y dinámicos por naturaleza, tienen que poder afrontar con garantías de éxito sus misiones tanto en el presente como en ese futuro incógnito, adaptándose sin solución de continuidad a las circunstancias cambiantes. La propia Ley antes men- 
cionada constituye un buen ejemplo de este proceso de adaptación a los tiempos actuales, en los que la propia sociedad ha demandado el abandono del modelo tradicional de servicio militar obligatorio.

Mas, para adaptarse al cambio, es obvio hay que detectar que se está produciendo este cambio, lo que exige una permanente reflexión basada más en el conocimiento que en la intuición. Y si no se quiere perder el compás, asumiendo riesgos innecesarios, esta detección ha de ser precoz porque las Fuerzas Armadas, por su propia naturaleza y por la de sus medios específicos de acción, arrastran una gran inercia que dificulta su cambio. Pensemos, por ejemplo, en un costoso sistema de armas cuyo ciclo de vida puede fácilmente prolongarse durante varias décadas y cuya aparición en las unidades operativas suele ir precedida de una amplia etapa de desarrollo conceptual pero que, al mismo tiempo, puede quedar obsoleto de la noche a la mañana ante la irrupción sorpresiva de un desarrollo tecnológico innovador. Las armas de hoy, que fueron diseñadas y desarrolladas ayer, seguirán estando en uso en un mañana lejano y si queremos que al llegar a ese punto del horizonte sigan siendo útiles tendremos que aproximarnos y definir conceptualmente lo más posible el escenario del mañana. Otro tanto podemos decir de nuestros cuadros de mando cuyo estilo e ideas se están forjando hoy en nuestros centros de formación y que han de ejercer la alta dirección de nuestros Centros y Unidades en un horizonte temporal aún lejano, en unas circunstancias, a buen seguro, totalmente distintas de las actuales.

En estas reflexiones partiremos de la situación actual y exploraremos algunas herramientas de las que nos podemos valer -más allá de la intuición - para detectar el cambio e intentar aproximarnos de modo racional a ese porvenir ineludible al que nos vemos abocados pero que, en cierta forma, podemos - y debemos- amoldar a nuestros deseos.

\section{La situación de partida}

En su conocido libro "Guerra y Antiguerra» ${ }^{2}$, Alvin y Heidi Toffler hacen extensiva a las Fuerzas Armadas la conocida teoría de las tres oleadas. Según ellos los Ejércitos, al igual que el resto de la sociedad, se encuentran hoy en los albores de la transición de la era industrial a la era de la información, hecho que se refleja en la renovación de sus conceptos. Están así pasando de la masificación de sus efectivos a la individualización y especialización; de la cantidad a la calidad; de las fórmulas doctrinales genéricas y rígidas aplicables en cualquier 
situación a la precisión quirúrgica a la medida, que ataca el punto crítico — sólo posible con el conocimiento-. Del dominio del músculo, la fuerza bruta, se está pasando al dominio de la información, precursora del conocimiento. Esto, por si solo, implica una revolución sin límites en todos los campos de la ciencia y el arte militares y abre paso a un inmenso abanico de posibilidades.

Los Ejércitos, al igual que las Naciones, se encuentran en distintas etapas de este proceso evolutivo y los mas desarrollados han empezado ya a hacer uso de los recursos y procedimientos tecnológicos más avanzados como tenemos ocasión de comprobar, casi a diario, si seguimos la evolución de los conflictos en curso.

Pero los Ejércitos, incluso los más desarrollados, siguen dependiendo básicamente de unas armas tradicionales, herederas de las de la $2^{\text {a }}$ Guerra Mundial (aunque sus rendimientos se hayan hecho superiores en muchos órdenes de magnitud). Su fuerza reside, como siempre, en la capacidad de choque de sus medios acorazados y mecanizados, en la potencia de fuego de sus armas, en el desplazamiento oportuno de sus masas de maniobra. Es cierto que ha aumentado en alto grado la movilidad, la velocidad, la protección, la capacidad de maniobra, la potencia de fuego de las Unidades; sin embargo, los conceptos tácticos que hacen uso de ellas apenas si han experimentado variación. Como suele suceder, el avance conceptual en el empleo de los medios va por detrás del propio desarrollo de estos medios aún cuando, paradójicamente, haya sido su precursor. Mas aún, los medios propios de la nueva era, que pueden dar lugar a formas de librar el combate totalmente distintas a las que hasta ahora se conciben, aún no han hecho mas que una tímida aparición. Si lo que se pretende con la fuerza militar es doblegar la voluntad del adversario y sentando como premisa que existirán en el futuro ocasiones que sigan haciendo necesaria esta aplicación de la fuerza para 'resolver conflictos en las relaciones entre países ¿no habrá formas, todavía no exploradas, de forzar esta voluntad con otras manifestaciones de poder militar?

La clásica preparación artillera de los viejos manuales tácticos, con la que se pretendía ablandar la capacidad de defensa del adversario por medio de los efectos de los fuegos, siempre precursores del ataque y la ocupación del terreno, ha sido ampliada por otro tipo de fuegos, más precisos, potentes y profundos, pero fuegos al fin. La doctrina norteamericana del «AIRLAND BATTLE», base de las ideas militares occidentales a partir de la década de los 80 , instauró el principio del ataque sincronizado en toda la profundidad, con medios adecuados a cada escalón. 
Así el viejo concepto que se aplicaba anteriormente sólo al ámbito táctico, fue ampliándose al espacio estratégico y al operacional. Aparecieron nuevos vectores, como el moderno misil crucero o las armas de precisión sobre plataformas aéreas, pero su fundamento último -ablandar la voluntad del adversario para disminuir su capacidad de resistencia, la posibilidad de aferrarse al terreno ocupado, y aislarle de su retaguardia - permanece intacto. Han aumentado, es cierto, las profundidades de actuación y si antes se trataba de cegar, antes del ataque, al adversario para que no pudiera ejercer un control eficaz de sus defensas y si se atacaba a su artillería para acallarla, el ataque de hoy a sus elementos de mando y control, a sus defensas antiaéreas, a sus órganos de decisión en los momentos iniciales del conflicto no deja de responder a las mismas ideas, llevadas a otra escala, hecha posible, sobre todo, por la tecnología de la información. Las V2 de hace 50 años, convertidas hoy en misiles crucero siguen atacando a la profunda retaguardia enemiga, pretendiendo doblegar, igual que antaño, la voluntad política para evitar, si es posible, tener que llegar al choque de las masas terrestres, único procedimiento resolutivo conocido hasta la fecha.

Un análisis superficial de los recientes conflictos armados puede dar lugar a conclusiones erróneas o simplistas, a la impresión de que todos estos conceptos han sido ya superados. La aplastante superioridad tecnológica y el uso intensivo de las herramientas basadas en la información, en una situación de total asimetría de fuerzas, contra adversarios que se encuentran sensiblemente retrasados en su desarrollo tecnológico, ha permitido llevar a la práctica concepciones estratégicas y operacionales en unas condiciones imposibles de repetir si los adversarios en lid hubieran estado cualitativamente más equilibrados. $\mathrm{Y}$ ni siquiera en estas condiciones óptimas, desde una posición de absoluta superioridad, se han logrado los efectos resolutivos que se pretendían lograr. De la tierra, en muchos casos quemada, siempre pueden resurgir nuevos brotes de violencia, solo controlables «in situ», que obligan a la postre a la permanente ocupación del terreno por las únicas fuerzas capaces de hacerlo durante tiempo prolongado, las terrestres. Nada ha sustituido, hasta ahora, al viejo axioma: para dominar un espacio hay que poner el pie en él.

$\mathrm{Ni}$ la «ciencia» aplicada a los medios militares ni el propio «arte militar» que hace uso de estos medios ha entrado de pleno en la era de la información en cuyos albores explosivos nos encontramos. La adaptación al futuro, apenas si ha sido iniciada en este campo, en el que no hemos hecho sino extrapolar viejas ideas, quizás porque a caballo 
de la asimetría de las voluntades enfrentadas no haya habido necesidad de buscar soluciones más imaginativas.

A diferencia de lo que ocurrió en las últimas décadas en las que coexistieron dos bloques adversarios de capacidad similar, hoy ha desaparecido el equilibrio estático emparejado a la bipolaridad y la situación actual se caracteriza por una gran dinamicidad, ambigüedad e incertidumbre. No podemos por lo tanto seguir basándonos en concepciones doctrinales simples, en fórmulas universales que se aplicaban a situaciones casi siempre previstas, sino que tendremos que atender a una gran variedad de matices con respuestas flexibles, capaces de abarcar una amplia gama de opciones.

Hemos entrado en un nuevo mundo, mucho más incierto, en el que los riesgos a la seguridad se han multiplicado. «Este nuevo clima de distensión no ha podido evitar... la aparición de conflictos de limitada entidad pero de notable repercusión internacional, ni el riesgo de proliferación de armas nucleares, biológicas o químicas, y de sus medios de lanzamiento. Tampoco ha conseguido eliminar las amenazas potenciales contra los intereses estratégicos de las naciones» ${ }^{3}$. Al tiempo, el espectro de la violencia se ha desplazado hacia el dominio de los llamados «conflictos de baja intensidad» y se puede afirmar que aún cuando ha cambiado el peso relativo de los dos factores clave - probabilidad e intensidad del conflicto- su producto final apenas si ha experimentado variación. Alejado el temor al holocausto nuclear, que se percibe poco probable, ha disminuido el umbral de disparo del recurso a la fuerza para dirimir las discrepancias, de modo que los conflictos locales se han ido haciendo más y más probables.

A esto hemos de añadir el nuevo principio de orden mundial que se ha abierto paso, el de la "injerencia legítima ", que al amparo de la ONU propugna impedir por la fuerza la «violencia ilegítima» implícita en la mayoría de los conflictos locales, que ha conducido a los desmanes por todos conocidos. Ha surgido una nueva ética de empleo de la fuerza, que so pretexto del respeto a los derechos del ser humano, no solo hace válido el recurso a ella, sino que la impone cuando estos se ven transgredidos.

Este panorama internacional ha sido certeramente definido por el Dr. Henry A. Kissinger como «un nuevo desorden mundial» ${ }^{4}$, desorden en el que los actores clásicos tratan de encontrar, incluso a codazos, $\mathrm{su}$ puesto en el escenario.

El soldado ha sido siempre el elemento esencial de los Ejércitos. Sumido hoy en un mar de información que le llega por todos los medios imaginables las 24 horas del día es ante todo, como todos los ciudadanos, 
un ser «informado» que vive en una sociedad democrática y como tal, crítica y consciente de sus derechos. Por ello, mas que nunca, en la esencia de la profesión militar han de hallarse unos valores éticos que impulsen al soldado a actuar por convicción cuando, voluntariamente, haya decidido el ciudadano dedicarse a la defensa de la Nación. Desarrollar estos valores éticos en nuestros profesionales de modo que los asuman con naturalidad, sin imposiciones, es el gran reto al que todos, empezando por la propia sociedad, nos enfrentamos, para elevar a un nivel superior en la escala de valores un honroso medio de ganarse el cotidiano sustento.

El soldado ha dejado de ser la fuerza bruta, la mano de obra abundante, casi ilimitada, de los ejércitos de masas para integrarse más y más en sistemas complejos que requieren gran pericia y habilidad de manejo. «La Guerra del mañana tenderá esencialmente a alejar al hombre del campo de batalla. Absorbido en la interface hombre-máquina, el soldado ejecutará, ante todo, una guerra de información. Los primeros guerreros de la información (I-warriors) se están ya formando en la Universidad de Defensa Nacional de Washington» ${ }^{5}$. Hacia esta especialización del combatiente empuja, además, la reducción de los efectivos de los Ejércitos. Para hacer del soldado un operario experto, que ha de conocer con detenimiento los costosos medios que se ponen en sus manos, el Ejército ha de ejercer una gran labor de formación que, como valor añadido, devolverá a la sociedad civil hombres íntegros y preparados para ejercer las más diversas funciones. La formación del soldado profesional adquiere, pues, una nueva dimensión y exige que se acometa con gran visión de futuro.

La profesionalización es un reto sin par. Quienes durante muchos años hemos vivido el "ciclo corto» del soldado que venía a cumplir su servicio militar, soldado al que apenas si había tiempo de adiestrar antes de que se reintegrase a la vida civil para, a semejanza de Sísifo, iniciar cíclicamente la penosa cuesta arriba y empezar a instruir a una nueva "quinta", nos encontramos con un soldado distinto, que debe ser capaz de asumir cometidos cada vez más complejos en un campo de batalla dominado por la técnica. En estos nuevos cometidos se ha producido un salto cualitativo, cuyos límites apenas vislumbramós. El soldado de hoy, la nueva generación de tropa y cuadros de mando ha de prepararse para estar en condiciones de afrontar ese mañana incierto, de límites difusos. Al igual que la industrialización multiplicó el rendimiento del operario, las nuevas técnicas aplicadas al arte de la guerra harán factible elevar hasta límites ahora insospechados la 
capacidad del combatiente, permitiendo compensar con creces la escasez de efectivos con su tecnificación.

Cierto es que los límites cuantitativos establecidos por la Ley constituyen otra referencia clave. Con gran sentido de anticipación, el conocido Plan Norte ha conducido hacia un Ejército de Tierra de dimensiones cuidadosamente estudiadas, afrontadas con realismo, ajustadas a la realidad social, demográfica y económica de nuestra Nación y a su peso en el concierto internacional. En el difícil proceso de compensar con calidad lo que se ha reducido en cantidad, el desarrollo cualitativo ha de ser una constante en nuestros Objetivos de Fuerza que, no olvidemos, han de estar adecuados a la estrategia de Defensa, y racionalmente ponderados con los componentes navales y aéreos, para constituir conjuntamente el «eficaz instrumento de disuasión, prevención y respuesta» que preconiza la Directiva de Defensa Nacional.

Mas «disuasión prevención y respuesta» no son conceptos abstractos, sino que apuntan hacia unos riesgos y amenazas, concretos en lo posible, cuya definición previa entra de lleno en el ámbito de la Inteligencia Militar.

El planteamiento de nuestra Defensa en un entorno colectivo fija también unos límites, al tiempo que introduce un factor adicional de incertidumbre. Los riesgos propios quedan englobados en una sombrilla mucho mas amplia y sutil, al igual que la organización militar que los ampara. Coloquialmente hablando, «lo que nos vamos a jugar es menos pero lo vamos a hacer muchas más veces». Y ello nos obliga a considerar seriamente el estado continuo de preparación en el que deben hallarse unas Fuerzas con vocación permanente de proyección hacia el exterior, integradas en un atrayente proyecto de defensa transnacional.

\section{Consideraciones sobre la Inteligencia Militar y la Planificación}

Fijado el entorno defensivo en que ha de cumplir su misión, la entidad y el carácter profesional del Ejército, éste ha de ser dotado, adiestrado y llegado el caso, utilizado. Estas actividades primarias, que se desarrollan sin solución de continuidad, han de traducirse en unos planes a corto, medio y largo plazo, planes que a su vez se basan en unas premisas o escenarios de actuación. Estas premisas, escenarios, o factores, en suma, en los que han de basarse las decisiones son de índole muy variada. Cuando se atiende a la definición de escenarios relativos a riesgos y amenazas y a la determinación de las 


\section{Inteligencia y planificación en el Ejército}

características de los posibles Teatros de Operaciones en los que nos podemos ver implicados entramos en el campo de la Inteligencia militar, que contemplaremos con mayor detalle.

En definitiva, son dos los problemas fundamentales a los que tiene que atender el planificador, al más alto nivel: determinar y constituir el Objetivo de Fuerza y prever el empleo de esta Fuerza, ya dotada de medios adecuados, en los futuros escenarios.

Inteligencia, en su acepción militar, es conocimiento. De todos los factores que un Jefe militar debe considerar antes de tomar sus decisiones, existen algunos que se escapan de su entender ordinario y cuya definición, por su naturaleza, exige un procedimiento especial. Son los que se refieren a otras Naciones o Alianzas con los que puede llegar a enfrentarse la propia Nación en una crisis armada, a los riesgos o amenazas potenciales o reales a la propia seguridad y al ámbito, al entorno en el que se han de planificar y en su caso llevar a efecto operaciones militares. Del conocimiento de estos factores y de su determinación y presentación en forma, lugar y momento adecuados entiende la Inteligencia Militar.

Los dominios de esta Inteligencia Militar son muy amplios. La Inteligencia Militar Terrestre debe satisfacer en tiempo oportuno las necesidades de información del Jefe y resolver sus incertidumbres para permitirle, en primer lugar, planificar la organización, la constitución y el adiestramiento de unas Fuerzas cuantitativa y cualitativamente adecuadas, lo que se viene en denominar el "Objetivo de Fuerza" (Inteligencia Militar General). Fijado éste, la Inteligencia Militar Operativa trata de preparar el empleo de la Fuerza y aplicar, llegado el caso, dicha Fuerza. Esta preparación y empleo operativo supone para los Estados Mayores el planeamiento de contingencias, el planeamiento de campañas, la proyección de fuerzas, la ejecución de operaciones y la recuperación de las fuerzas proyectadas.

Es por lo tanto la Inteligencia una actividad continua en el tiempo, que a los niveles de decisión más elevados ha de ejercerse de forma activa desde la normalidad de la paz ya que, además de adelantarse al futuro, ha de evitar la sorpresa estratégica y alertar en tiempo oportuno a los sistemas de reacción. Y que se prolonga en el Campo de Batalla cuando, tomada la decisión de emplear la Fuerza, se prepara e inicia el despliegue de ésta en un Teatro o Zona de Operaciones.

Una primera estructuración de estos conocimientos puede basarse en el nivel de decisión al que afectan. Nos encontramos así con la Inteligencia Estratégica, la Inteligencia Operacional y la Inteligencia Táctica. 
La Inteligencia Estratégica, en su faceta militar, es la necesaria para la formulación de la política y planes militares a niveles nacional e internacional, y en Teatros de Operaciones. Es, por naturaleza, materia conjunta de todas las Fuerzas Armadas e implica la utilización de medios, especialmente humanos, que rebasan el ámbito puramente militar.

Esta Inteligencia Estratégica ${ }^{6}$ abarca todos los factores que configuran las posibilidades, las vulnerabilidades y las posibles líneas de acción de las naciones extranjeras, así como la naturaleza e infraestructura de los posibles Teatros de Operaciones.

A la definición de las «posibilidades» y «vulnerabilidades» se llega tras considerar y analizar los puntos fuertes y débiles de las naciones en estudio. Y una «posibilidad» tomará la consideración de « riesgo o amenaza» cuando en la potencia extranjera que se esté analizando pueda desarrollarse una componente volitiva, una intencionalidad de uso de la fuerza en contra de los intereses propios, nacionales o coaligados.

Son múltiples los factores que tiene que considerar la Inteligencia Estratégica, como variados son los campos que, en su conjunto, determinan las capacidades militares de una nación ${ }^{7}$. Existe así una componente biográfica, que atiende al devenir de las ideas de sus líderes y el grado de agresividad que acarrean. El análisis histórico fija su atención sobre «los conflictos nacionalistas, intereses hegemónicos, deseos de revancha, temorès o recelos, rivalidades religiosas, rivalidades étnicas o de minorías, con gran capacidad para mantenerse latentes durante largos periodos históricos» ${ }^{8}$. La componente geográfica, estudia todas las ramas de esta disciplina deduciendo las correspondientes servidumbres y ventajas geopolíticas. El grado de desarrollo de la infraestructura de Transportes y Comunicaciones es otro claro indicativo del potencial nacional. La componente sociológica analiza las características cualitativas y cuantitativas de la población, su distribución, su presión demográfica, su estado sanitario y educativo, y sobre todo, la contribución de todos estos elementos a la determináción del carácter nacional y su posible actitud ante el conflicto armado. La componente política fija su atención en la situación interna y en las orientaciones defensivas en el marco de tratados y alianzas así como en la propia actitud ante el empleo potencial de la fuerza. La componente económica permite determinar la capacidad para armar y mantener unas fuerzas armadas, las vulnerabilidades en tiempo de guerra y las posibilidades de movilización de recursos económicos. Es fundamental estudiar la componente científica, con su aplicación a la tecnología militar, al desarrollo de nuevas armas y equipos, al desarrollo 
global de la nación. Y, finalmente, la componente de las Fuerzas Armadas, cuya entidad, organización, despliegue, eficacia, y actividades, su Orden de Batalla en suma, orientan las labores del planificador.

Aún cuando trataremos con mayor detalle los «productos» a que da lugar la inteligencia estratégica, adelantaremos que fundamentalmente debe estimar las posibilidades y aventurar las intenciones de los países extranjeros, advirtiendo su posible evolución. En definitiva, debe definir lo mas precisamente posible un escenario futuro.

Detectado un riesgo o amenaza, materializados éstos en una situación de hostilidad y decidido el empleo operativo de una Fuerza, la Inteligencia debe poner a su Jefe, Operacional o Táctico, en disposición de saber con quien tiene que enfrentarse, en dónde y en qué condiciones. Análogos condicionantes, con sus matices específicos, se presentan cuando se trata de intervenir en operaciones «no bélicas», como las de interposición, ayuda humanitaria, mantenimiento de la paz etc. Establecido el contacto con el adversario, se precisa un conocimiento lo mas detallado posible de la situacióĩ actual de los factores citados. Surgen así la Inteligencia Operacional y la Inteligencia Táctica, que podemos englobar en un concepto más amplio: el de «Inteligencia en el Campo de Batalla».

La Inteligencia Operacional proporciona datos para determinar aquellos aspectos del adversario, tales como su centro de gravedad, sus líneas de operación y sus puntos culminantes, que afectan a las operaciones como un todo, mientras la Inteligencia Táctica está más relacionada con el conocimiento de las características generales y militares del terreno, la influencia de la meteorología en el campo de batalla, el despliegue y composición de las unidades enemigas y sus vulnerabilidades. El estudio de los factores y valoración de la situación en la Inteligencia Operacional se basa en consideraciones amplias, como los aspectos políticos, sociológicos, económicos, históricos, tecnológicos, y psicológicos además de los militares y geográficos a gran escala ya mencionados entre los componentes de la Inteligencia Estratégica. La Inteligencia Táctica estudia el detalle de la geografía y la meteorología locales y tiene en cuenta la valoración de la situación de su escalón operacional superior.

La Inteligencia Táctica se desarrolla en plazos en tiempo breves, que se corresponden con la rapidez de la evolución de la situación cuando las unidades combaten, llegan al combate o están próximas a éste. La Inteligencia Operacional necesita plazos más dilatados en razón de la complejidad de los análisis a realizar, pero sus conclusiones 
son más duraderas por ser más lenta la evolución de la situación en este nivel.

Ya hemos apuntado que en los niveles tácticos la Inteligencia ha perdido hoy en día gran parte de su carácter predictivo (ya que los modernos medios de vigilancia del Campo de Batalla permiten "ver» dónde está y qué hace el enemigo, con lo que no es necesario conjeturar sobre éstos extremos). Por el contrario la Inteligencia Operacional es de naturaleza especulativa y por ello lleva implícitos elementos de riesgo o factores de incertidumbre pues debe contemplar la campaña introduciéndose en la mente y viendo a través de los ojos del Jefe enemigo, sin verse constreñida por nociones preconcebidas propias.

\section{Los productos de la Inteligencia Militar ${ }^{9}$}

La generación del conocimiento base para la toma de decisiones -la producción de Inteligencia- exige una metodología. Se materializa ésta en una serie de labores que se suceden siguiendo lo que se ha dado en llamar el «ciclo de inteligencia». Al final de este proceso la información en bruto, inicialmente disponible o específicamente buscada, se verá transformada en unos productos que pueden revestir diversas formas.

La «inteligencia actual» facilita el seguimiento de los acontecimientos en curso, mediante noticias y comentarios que se entregan en forma de boletines periódicos o «briefings». Puede extenderse a trabajos puntuales más detallados sobre determinados tópicos de actualidad, o referencias utilizables en reuniones, discusiones, etc. De naturaleza perecedera, proporciona una buena ocasión para el contacto interactivo entre el productor y el usuario de inteligencia e impone una labor muy exigente a las organizaciones de inteligencia por la presión a la que se ven sometidas en términos de cumplimiento de plazos temporales.

La «inteligencia básica» es el resultado del análisis de grandes volúmenes de información de todo tipo, informes, datos, publicaciones, imágenes... Nutre el «banco de datos» al que en primera instancia acudirá el analista cuando se le plantee un problema específico. Estos bancos de datos contienen desde el «orden de batalla» de los ejércitos hasta las características de sus armas, junto con toda la información relativa a los diversos componentes de la inteligencia estratégica a los que hemos hecho mención.

La «inteligencia científica y técnica» es inteligencia básica, pero su naturaleza exige disponer de analistas con una especial formación 
en estos campos, capaces de seguir la evolución de todos aquéllos desarrollos de especial significación militar.

Una de las funciones más críticas de la inteligencia militar es la relacionada con los «indicadores y alertas». Tiene por fin evitar las sorpresas, mediante un seguimiento permanente de la situación. Para ello se preparan listas de «indicadores» que hacen saltar la alarma cuando se detectan las condiciones previstas. El repentino acuartelamiento de determinadas unidades o el incremento del tráfico de telecomunicaciones pueden, por ejemplo, ser indicio de una crisis inminente que obligue a adoptar medidas preventivas.

La «inteligencia de objetivos» identifica las características de la infraestructura y despliegue adversario y los puntos susceptibles de ser atacados. Apoya el planeamiento de las misiones y valora los resultados de los ataques. Las modernas armas tipo «crucero», por ejemplo, exigen un preciso conocimiento previo de los objetivos susceptibles de ser atacados.

Citaremos, por último, uno de los «productos» más importantes: los «juicíos» o «estimaciones» de Inteligencia, que pueden ser muy amplios o por el contrario atender aspectos muy concretos. Específicamente destinados a proporcionar predicciones sobre el futuro, desde el inmediato para el Jefe táctico, hasta con décadas de anticipación al mas alto nivel, estos juicios constituyen la base de inteligencia en la que se apoya la planificación a largo plazo del Objetivo de Fuerza.

\section{La producción de Inteligencia ${ }^{10}$}

Para elaborar sus productos, el analista de inteligencia se vale de un proceso mediante el que extrae de la información en bruto el contenido relevante para la formulación de las políticas o planes en cuestión.

Se inicia este proceso con una cuidadosa consideración de la finalidad y ámbito del "producto» que se necesita, cuyo contenido puede ser decidido por el analista en función de su estrecha relación con quien vaya a hacer uso de la inteligencia o ser específicamente determinado por éste. El analista reunirá cuantos datos considere relevantes y buscará por medio de investigaciones adicionales, encomendadas a sus órganos de obtención, la información complementaria que necesite. Una vez acumulada, valorará su precisión, su fiabilidad y su importancia en relación con el tema que esté considerando e intentará establecer una hipótesis coherente y lógica en la que encaje la información que ha ido valorando, comprobando la consistencia de sus razonamientos 
y determinando las implicaciones correspondientes. Este proceso continuará hasta que el analista se sienta capaz de extraer las conclusiones que den respuesta a los interrogantes inicialmente planteados. La precisión del producto obtenido será función de la calidad y cantidad de la información utilizada en su preparación, y de la experiencia del analista.

Aunque el proceso es secuencial - de la obtención de datos a la entrega del producto final-, los pasos de la secuencia no son rígidos. En todo este proceso puede haber cierta realimentación; por ejemplo, al reunir y analizar datos se revelarán con frecuencia lagunas de información que exigirán la captación de más datos. El proceso, en general se desarrolla en un ciclo de cuatro pasos: dirección, obtención, elaboración (correlación y análisis) y difusión.

El flujo vital de toda organización de inteligencia es la circulación ininterrumpida de información relevante, información que en unos casos puede tener interés inmediato y en otros revestir importancia a largo plazo.

Paso previo al proceso de obtención de información es la búsqueda y explotación de la ya archivada en bibliotecas, bases de datos, etc. Estos trabajos iniciales proporcionarán un marco de referencia y revelarán las carencias de datos, que habrá que solventar recurriendo a los especialistas en su obtención. La información será buscada y obtenida de forma sistemática utilizando todas las fuentes disponibles: fotografías o imágenes, documentos, señales de telecomunicación, actuación personal de agentes, etc.

A esta obtención de datos sucede la organización de la información disponible, reuniendo todos los elementos relevantes por materias y disponiéndolos de manera coherente, haciendo destacar los aspectos más señalados y extrayendo unas primeras conclusiones sobre las relaciones entre los hechos y sus implicaciones. Se trata, en definitiva, de preparar toda la información de forma que pueda ser considerada globalmente.

El análisis de inteligencia constituye un proceso intelectual particular con el que se pretende establecer el significado de aquéllos acontecimientos externos de relevancia para los órganos de decisión mediante un estudio ordenado y lógico de los factores pertinentes. El análisis se basa en la descomposición de un problema en sus componentes de menor rango, manipulando mentalmente los datos hasta llegar a conclusiones o generalizaciones por deducción o inducción.

La semejanza entre la metodología y los procesos del análisis de inteligencia y la investigación documental en otras disciplinas es in- 
discutible. Pero la singularidad del análisis de inteligencia estriba en que su único objetivo es determinar, lo mas precisamente posible, las futuras capacidades e intenciones de países o ejércitos extranjeros. Predecir con éxito estas intenciones y posibilidades exige un conocimiento especial para comprender todas las razones que motivan a las naciones. Esta destreza, este conocimiento profundo es el que distingue al analista de inteligencia que es, en suma, intérprete de culturas y problemas ajenos; su objetivo no es tanto descubrir la verdad de un asunto como determinar su significado.

El analista debe adentrarse en el futuro todo lo que le permitan los datos de que dispone. Partiendo de una descripción de la situación actual, tan precisa como sea factible en función del tiempo y la información disponibles, tratará de discernir el porvenir. Dentro de ciertos límites, le será posible especular, pero con precaución. Sus estimaciones nunca deberán desviarse de los hechos que las sustentan.

\section{La Inteligencia y la Prospectiva}

Todas las actividades de Planeamiento, por dispares que sean, tienen por factor común tener que recurrir en mayor o menor grado a la predicción, a una reflexión sobre el futuro que trae pareja su correspondiente incertidumbre. Exigen situarse en el mañana, imaginarse en una situación y adoptar decisiones adecuadas, reflejadas en Planes, que nos han de llevar del hoy al mañana previsto en condiciones ventajosas para afrontarlo con garantías de éxito.

En esta aproximación al futuro podemos seguir dos caminos, no excluyentes entre sí. El primero de ellos, es el clásico. En él partimos del ayer, estudiamos el paso del ayer al hoy, determinamos lo que ha permanecido constante y la ley de variación de lo que ha experimentado cambio y, extrapolando, llegamos a establecer las "hipótesis" sobre las que basaremos nuestras decisiones. Es un método útil a corto y medio plazo, puesto que las tendencias extraídas del análisis apenas si van a sufrir inflexiones y, si lo hacen, la desviación de lo "previsto" apenas tendrá importancia.

Al ir alejándonos en el tiempo, al subir el nivel de planificación y pasar a espacios y tiempos más amplios, escalando del campo táctico al operacional y más aún, al estratégico, la proyección del pasado hacia el futuro se hace más y más imprecisa. Al recorrer las curvas de las «tendencias» pueden aparecer no una, sino múltiples inflexiones que pueden conducir a conclusiones desviádas. La extrapolación del 
pasado no conduce necesariamente a un futuro «fiable» en el que podamos basar nuestras decisiones a largo plazo. Tendremos que acudir a otras herramientas, a una segunda vía: la "prospectiva», en la que efectuamos un camino inverso aproximándonos al presente a partir de unos futuros posibles, ordenados por orden de probabilidad. Como no se trata de «conjeturar intuitivamente», sino de «predecir científicamente», la actitud prospectiva no está ni mucho menos reñida con el proceso de «inteligencia» que someramente hemos descrito; por el contrario, inteligencia y prospectiva comparten un espacio en el que sus efectos son sinérgicos, se refuerzan mútuamente. Podemos por lo tanto hablar de una «inteligencia prospectiva».

Ante todo ¿en qué consiste esta actitud prospectiva? El General Torrón ${ }^{11}$ nos dice:

«La actitud prospectiva es definida por Gaston Berger como un «etat d'esprit» ejercido sobre cuatro pilares: ver a lo lejos; ver con amplitud; analizar en profundidad; hacerlo de forma aventurada.

El primer pilar implica el largo plazo, que es donde la prospectiva tiene su campo de actuación.

El segundo supone el análisis global e interdisciplinario propio del enfoque sistémico que... se hace imprescindible ante la complejidad del futuro.

El tercero (analizar en profundidad) exige el empleo de criterios y métodos racionales que con base científica alejan la prospectiva de la adivinación. Por último, el cuarto principio supone el uso fructífero y creativo de la imaginación que debe acompañar a todo análisis prospectivo...»

Ver con amplitud supone para el analista de inteligencia una cuidadosa consideración de todos los factores relevantes, de todos los componentes en el ambiente multidisciplinar en el que se desenvuelve su actividad. Consideración que, de acuerdo con el cuarto principio, ha de hacer con una mente totalmente abierta y sin dejarse llevar de ideas preconcebidas. Analizar profundamente le supone, aparte del rigor científico de sus juicios, incorporar a su metodología unas técnicas auxiliares adecuadas.

Podemos por lo tanto considerar dos facetas en el binomio INTELIGENCIA-PROSPECTIVA: la inteligencia es una técnica de apoyo al planeamiento prospectivo y por otra parte la aplicación de técnicas prospectivas facilita la elaboración de inteligencia. Trataremos seguidamente estas dos facetas, basándonos en unos modelos clásicos. 


\section{Inteligencia y planificación en el Ejército}

\section{La Inteligencia en apoyo del planeamiento prospectivo: El Planeamiento Basado en Supuestos ${ }^{12}$}

Esta técnica de prospectiva fue desarrollada a instancias del Ejército de los EE.UU. por la Corporación RAND. Su filosofía queda perfectamente definida en el sumario de la publicación:

«La planificación de la Seguridad Nacional en el pasado inmediato se ha basado en la definición del mundo futuro más probable, extrapolado de las tendencias actuales. En una situación estable y predecible, como la de la era de la Guerra Fría, tal enfoque era razonable. Pero en tiempos muy inciertos, como los que vivimos hoy, no existe un sólo mundo futuro altamente probable. Los planes que se basan en la probabilidad de un mundo en particular corren el riesgo de ser severamente incorrectos».......

El Planeamiento Basado en Supuestos empieza por definir en qué hipótesis se basan los planes de una organización, o esta misma organización, para pasar a identificar las vulnerabilidades o posibles fallos de estos supuestos en el horizonte temporal que se contempla. Se estudian y determinan a continuación los indicativos del cambio, para pasar a establecer dos tipos de medidas: unas encaminadas a evitar el cambio; otras que tienen por objeto, si aquél es inevitable, adaptar a estos cambios los planes de la organización, o la propia organización. Se trata, en definitiva, de asumir una actitud activa ante el futuro, tratando de moldearlo a nuestro deseo. Es la selección y búsqueda del futuro deseable a partir del hallazgo de los futuros posibles. De todo este proceso, los tres primeros pasos tienen gran relación con la «inteligencia». El cuarto paso ofrece un matiz que fácilmente podría adentrarnos en las «operaciones especiales de inteligencia», de carácter más o menos clandestino, que por las profundas consideraciones de todo tipo que entrañan se sale de los ámbitos de este trabajo. El último paso podemos entroncarlo con las actividades de contra-inteligencia y seguridad por cuanto tienen de medidas defensivas.

Como hemos indicado, el Planeamiento Basado en Supuestos se inicia identificando los «supuestos» importantes. Un «supuesto» es una aseveración o aceptación como cierta de una característica del futuro que, explícita o implícitamente, subyace en los planes u operaciones de la organización. Esta aseveración puede manifestarse en forma de hechos o juicios, expresados en términos descriptivos, apreciativos, predictivos o explicativos. 
En esta definición podemos reconocer muchos, por no decir todos, de los elementos característicos de los productos de inteligencia a los que, como hemos visto, llega el analista tras procesar la información. El analista, al terminar su trabajo, plasma también sus conclusiones en unas hipótesis. La diferencia principal estriba en que en el Planeamiento Basado en Supuestos, estas características que definen un futuro subyacen explícita o implícitamente en los propios planes $u$ organización y el planificador los tiene que buscar y hacer aflorar, mientras que en el proceso de inteligencia se deberán hacer patentes con anterioridad a la formulación de los planes.

Entre todos los supuestos posibles, realmente ilimitados, deberán considerarse únicamente los verdaderamente importantes, entendiendo por tales aquéllos cuya negación conduciría a cambios considerables en los planes. El supuesto «las fuerzas terrestres combatirán bajo la amenaza de empleo por el adversario de armas bacteriológicas y químicas» es «importante», porque tiene una repercusión directa sobre las características, instrucción, dotación, etc. de dichas fuerzas; de no cumplirse el supuesto, los planes que contemplan su constitución y empleo experimentarían cambios considerables.

Determinar la naturaleza de estos supuestos representa, en términos de Inteligencia, el primer paso de todo su proceso, que se plasma en el establecimiento de los «elementos esenciales de información» o interrogantes fundamentales a los que quiere tener respuesta el Jefe antes de decidir y de los que arranca todo el ciclo de inteligencia. Llegar a definir explícitamente estos supuestos mediante el establecimiento de unas hipótesis es, a su vez, el fin último del proceso de inteligencia, en el que los productos fruto del análisis convierten los interrogantes iniciales en afirmaciones o negaciones que dan respuesta a esos «elementos esenciales de información».

La identificación de los «supuestos» es ejercicio que exige gran juicio y creatividad, a la que deben ponerse ciertos límites, debiendo conservarse finalmente solamente aquéllos que sean verdaderamente importantes. Es en definitiva el Jefe, a quien compete decidir, quien debe retener los supuestos que considere más relevantes para sus fines y quien, en consecuencia, asumirá el riesgo de desechar la consideración de los demás supuestos. Identificado y aceptado un «supuesto» importante, permanecerá como tal durante todo el horizonte de planeamiento, a no ser que la dinámica de los acontecimientos lo desborde.

Se considera que un «supuesto» es vulnerable si dentro del horizonte temporal del planeamiento pudiera producirse un hecho que lo denegara. 
La identificación de las vulnerabilidades de los supuestos es el siguiente paso del proceso.

La veracidad de los supuestos depende siempre del tiempo; cuanto mayor sea el plazo considerado, mayor será la probabilidad de su invalidación. La posibilidad de que se produzca un cambio en cierto punto del futuro depende de cuan alejado esté dicho punto del presente. Por ello, por ser cuestión de tiempo, solamente se consideran vulnerables aquellos supuestos que puedan variar sustancialmente dentro del horizonte temporal considerado.

Para llegar a determinar los elementos de cambio que hacen vulnerable a un supuesto se necesita tener una fuerte percepción de lo que podría ser el mundo al llegar a ese punto. No se trata de efectuar predicciones, sino de identificar qué acontecimientos, que cambios pueden acaecer; concentrándonos no en determinar qué es lo que "sucederá», sino en lo que «podría suceder». Un «elemento de cambio» es, por lo tanto, un acontecimiento o condición universal que cumple tres requisitos: supone una variación respecto al hoy; es factible dentro del periodo de planeamiento; y está relacionado con la organización y sus planes.

No hay un procedimiento único para detectar «elementos de cambio», y lo mismo pueden ser deducidos por extrapolación de tendencias que por la opinión de expertos, analogías históricas, simulaciones y juegos, etc. Nuevamente podemos acudir a la metodología de la Inteligencia, haciendo en este caso «inteligencia predictiva» para deducir y poner a disposición del planificador una lista depurada de «elementos de cambio».

A un supuesto lo hacen vulnerable los «elementos de cambio» que, de producirse, lo transformarían en inviable o incorrecto. Cada supuesto puede estar sometido no a uno, sino a múltiples «elementos de cambio»; cualquiera de ellos que se produzca, lo vulnerará. Una vez mas habrá que limitar, por consideraciones prácticas, el número de elementos para cada supuesto, ordenándolos por su riesgo, es decir, considerando para cada par «supuesto-elemento de cambio» la transcendencia del primero para los planes y la probabilidad de que se produzca el segundo.

Cuanto mayor sea la base de conocimientos que abarque este proceso, más eficaz será el Planeamiento Basado en Supuestos. Y cuanto más abiertas sean las mentes que intervengan en la deducción de vulnerabilidades, tanto mejor.

Fijados los «supuestos» y sus «elementos de cambio», hay que establecer un procedimiento para detectar la ruptura de las tendencias, el inicio del cambio. Para ello se utilizan «indicios». Un «indicio» es un hecho o umbral que revela con claridad que se está produciendo 
la vulneración de un supuesto. Esta indicación tiene que ser genuina y desprovista de toda ambigüedad. Aunque cada «supuesto» tiene sus propios «indicios» de vulneración, uno de estos puede afectar a varios supuestos; recíprocamente, cada supuesto puede ser relacionado con varios indicios, bien sea para aumentar la probabilidad de detección de la amenaza emergente, bien para poder observar desde diversas perspectivas si está siendo atacado un supuesto.

Recordemos que uno de los «productos» de inteligencia, es el establecimiento de «indicadores y alertas». Su similitud con los «indicios» es patente y es fácil que se puedan confundir unos y otros. Los «indicadores» hacen saltar la «alerta» del inminente acaecimiento de un hecho previsto, para el que hay una respuesta preparada. Los «indicios» advierten que nuestras hipótesis de planeamiento están dejando de ser válidas. La misma organización de Inteligencia que valida un supuesto mediante el seguimiento día a día de la situación puede detectar los indicios de que está iniciándose su vulneración.

Los dos últimos pasos del Planeamiento Basado en Supuestos estriban en el establecimiento de acciones que actúan sobre la vulnerabilidad de los supuestos (para oponerse al cambio) o sobre los propios planes u organización (para adaptarlos al cambio, si éste es inevitable).

El primer tipo de acciones exige un estudio previo para decidir si el potencial cambio del supuesto es favorable o desfavorable a los fines propios, identificando hasta qué punto puede controlar la organización al supuesto y definiendo las medidas precisas para ejercer dicho control si es preciso.

El segundo tipo de acciones tienen por objeto preparar a la organización para la eventualidad del fallo de uno de sus supuestos, revisando en consecuencia los planes. Para ello se debe desarrollar un universo ficticio, pero creíble, del que forma parte el supuesto fallado, y a continuación explorar dicho universo para extraer las conclusiones pertinentes.

Con estas medidas, preventivas o correctivas, dejamos esta metodología de planeamiento, resaltando el importante apoyo que al planificador le pueden prestar las organizaciones y técnicas propias de la Inteligencia y su analogía en muchos aspectos con la propia metodología de producción de Inteligencia.

\section{Aplicación de técnicas prospectivas a la producción de Inteligencia}

En líneas generales, podemos decir que existen dos tipos de análisis de Inteligencia: el análisis fundamentado, en el que todo cuanto se 
dice se basa en datos exactos, verificados y actuales; y el análisis especulativo, que trata de proporcionar respuestas fundadas en un conocimiento, generalmente bueno, del modo de pensar y actuar de la parte contraria y su comportamiento ${ }^{13}$. El análisis fundamentado proporciona «capacidades» y «posibilidades» actuales del país o Ejército estudiado. El análisis especulativo da un paso más hacia el futuro proyectando hacia él estas capacidades y posibilidades, llegando incluso a predecir «intenciones». Desde la perspectiva de la Inteligencia, podemos considerar a los «supuestos» del método de planeamiento antes estudiado como el resultado de un análisis especulativo. Por ello, por tratarse tan solo de "supuestos" han de estar sometidos a escrutinio, para determinar si son vulnerados y por lo tanto dejan de ser válidos como fundamento de los Planes.

Interesa, en todo caso, que estos supuestos, aun siendo producto de un análisis especulativo, anticipatorio del futuro, sean lo más estables posibles. Podemos acudir a determinadas técnicas que reduzcan la conjetura al mínimo indispensable, estrechando el espectro de todo lo posible a lo más probable. Ejemplo de estas técnicas son el Método Delphi y el Método de los Impactos Cruzados.

Según Saaty y Boone ${ }^{14}$ existen cuatro métodos factibles para pronosticar el futuro: por consenso, por extrapolación de tendencias, por análisis histórico y analogía y por la generación sistemática de vías alternativas hacia el futuro. Se considera que Delphi es la más prominente de las metodologías de consenso. Se pueden efectuar predicciones cuantitativas cuando existe información sobre el pasado, esta información puede expresarse en forma de datos y se supone que el futuro será una continuación del presente. Si se cree que no es así como se llegará al cambio y si no se dispone de datos, habrá que recurrir a métodos cualitativos

Delphi ${ }^{15}$ (en referencia al oráculo de Delfos) es el nombre que recibe un conjunto de procedimientos que tienen por objeto hacer aflorar y refinar la opinión de grupos de expertos. Descansa en la obtención de la respuesta estadística del grupo a una cuestión determinada, respuesta a la que se llega tras una secuencia de procesos iterativos en los que el resultado de cada uno de ellos sirve de información para el siguiente, Se extrae así la "sapiencia colectiva» de los expertos, que, aunque basada en sus opiniones intuitivas y subjetivas, será más fiable que dichas opiniones individualmente consideradas, dando por lo tanto lugar a un producto de mayor objetividad.

El método, desarrollado por la Corporación RAND a principio de los años 60 ha ido evolucionando hasta dar lugar a una familia 
de técnicas inspiradas en el Delphi original. Citaremos el «Delphi Convencional», el «Delphi de Política» y el Delphi de Decisión.

Las funciones principales del Delphi Convencional son la predicción y la estimación de parámetros desconocidos. Se utiliza preferentemente para alcanzar un consenso en la estimación de las fechas y las evoluciones en múltiples campos, en especial en la consecución de hitos a largo plazo en áreas de ciencia y tecnología. Al considerar los parámetros desconocidos, los expertos estiman qué niveles se alcanzarán en determinadas actividades, respecto a la situación actual. El Delphi de Política a diferencia, no busca un consenso, sino la generación de puntos de vista los más opuestos posibles en la resolución de un tema, para obtener cuantas opiniones se pueda. Su objetivo es actuar como foro de ideas y sacar a relucir toda la gama de opiniones, con los pros y contras de cada una de ellas. Finalmente el Delphi de Decisión se utiliza para alcanzar decisiones en el seno de un grupo con diversos intereses en la solución.

El método Delphi presenta el inconveniente de considerar los sucesos aisladamente, sin tener en cuenta su posible interacción. El Método de los Impactos Cruzados ${ }^{16}$, es una de las herramientas que viene a solventar este inconveniente. Utilizando también como base de partida la opinión de expertos, tiene por objeto dar información probabilística sobre futuros sucesos (supuestos que pueden ocurrir o no dentro del horizonte temporal considerado) y futuros escenarios (configurados por los sucesos). El método busca no solo la probabilidad de los sucesos en estudio, sino también la de los escenarios posibles y toma en consideración la existencia de relaciones entre sucesos, de tal modo que la ocurrencia de cualquiera de ellos puede aumentar o disminuir la probabilidad de los demás. Proporciona, pues, unos escenarios prospectivos jerarquizados por su probabilidad de acaecimiento.

Hemos ido apuntando las aportaciones que el analista de inteligencia puede hacer al responsable de la decisión, Jefe o planificador, en cuyas manos pone los productos que ha elaborado. Hemos indicado, también, la objetividad que debe caracterizar a todo análisis de inteligencia. Obligado el órgano de Inteligencia a presentar opciones de futuro puede y debe recurrir a estas, u otras, técnicas prospectivas de forma que las conclusiones que ofrezca sean colegiadas y fruto sinérgico de la experiencia del grupo. A la postre, sólo se trata de sustituir en los métodos que someramente hemos descrito el concepto de «experto» por el concepto de «analista». 


\section{Inteligencia y planificación en el Ejército}

\section{Una visión del futuro de la Inteligencia Militar ${ }^{17}$}

Como colofón a este recorrido por los mundos de la Planificación y la Inteligencia, no puede faltar una pequeña digresión sobre el propio futuro de esta disciplina en el ámbito de las fuerzas terrestres.

Un Sistema de Inteligencia se concibe como el conjunto de la doctrina, los procedimientos, las organizaciones y los medios humanos y materiales cuya misión es la producción de la inteligencia que necesitan los diversos escalones de mando para la planificación y ejecución de sus misiones. Una consideración prospectiva debe, necesariamente, contemplar todos y cada uno de los elementos componentes de dicho Sistema, así como las diversas fases del ya descrito Ciclo de Inteligencia.

En lo que respecta a los aspectos doctrinales y de procedimientos no parece que la evolución natural de la comunidad multinacional de inteligencia vaya a conducir a situaciones muy diferentes a las que se viven en la actualidad La Inteligencia Militar Operativa reforzará su carácter conjunto como conjuntas, es decir, con la participación de fuerzas aéreas, terrestres y navales, serán todas las operaciones que previsiblemente se hayan de realizar en el futuro. Ello no significa que haya que disminuir las capacidades especificas de cada uno los componentes de las Fuerzas Armadas; la Inteligencia General que precisa cada uno de los Ejércitos para la planificación y preparación de su Objetivo de Fuerza tiene un carácter muy particular y por ello cada Ejército debe, sin perjuicio de contribuir al fondo común, conservar la capacidad de elaborar este tipo de inteligencia en su propio beneficio.

La doctrina y los procedimientos estarán en completa sintonía con las de las organizaciones multinacionales en las que España se encuentra integrada; es la primera, esencial, condición para que la información, savia y elemento crítico de cualquier sistema de inteligencia, fluya en forma oportuna en el contexto de las comunidades nacional e internacional de inteligencia.

Los Ejércitos serán más pequeños y sus capacidades estarán basadas más en el conocimiento, producto de la información, que en los efectivos humanos y la cantidad de armamentos. Este supuesto conduce a la idea de una potenciación de las organizaciones de inteligencia militar. La defensa de los países se basa cada vez más, y es muy previsible que así continúe siendo, en la integración de sus capacidades puramente nacionales en una capacidad multinacional, en claro abandono de la autarquía en el ámbito de los ejércitos. Sin embargo, aún contribuyendo al esfuerzo defensivo común, las naciones nunca 
podrán abandonar su capacidad de elaboración de inteligencia en su propio provecho.

Las tendencias geo-estratégicas anticipan un mundo futuro en que el carácter cambiante, impredecible, de la situación actual no hará más que magnificarse; a ello se unirá la enorme cantidad de información que habrá de ser procesada. En este ambiente y pese a los avances tecnológicos, el analista de inteligencia seguirá siendo pieza clave del proceso de inteligencia; por muy complejos, potentes y numerosos que sean los medios materiales disponibles su capacidad de raciocinio es y seguirá siéndolo en el futuro, insustituible.

Muy probablemente, el mayor esfuerzo de imaginación que requiere el presente trabajo podría centrarse en los medios dedicados a inteligencia en un escenario futuro ${ }^{18}$. Son más que previsibles importantes avances tanto en lo que se refiere a los medios materiales dedicados a la obtención de la información, como al proceso de la misma y a la difusión de la inteligencia elaborada. Sin embargo, es preciso dejar, claro que la inteligencia futura no será mejor que la actual sólo porque existan mejores y más numerosos medios. Al igual que ocurre ahora, solamente mediante una oportuna, ponderada y coherente combinación de medios humanos y materiales, organizados adecuadamente, se conseguirá satisfacer las necesidades de inteligencia en el futuro.

Los potentes sistemas de procesamiento de información disponibles en la actualidad evolucionarán rápidamente, permitiendo la intervención del mando, del nivel que sea, en el ciclo de inteligencia en tiempo real. La interrelación e interoperabilidad del Sistema de Información de Inteligencia con el Sistema de Mando y Control global, del que forma parte, será completa; el mando correspondiente podrá exponer directamente sus necesidades de información sin necesidad de que intervengan terceros elementos. Formulada una necesidad de información, el Sistema de Inteligencia buscará la respuesta en sus propias bases de datos y en aquéllas otras nacionales o aliadas a las que se halle conectado. Si dicha acción proporciona los resultados requeridos, la inteligencia o información solicitada será remitida directamente al solicitante. La automatización de los procesos permitirá mantener programas de obtención permanente actualizados, que teniendo en cuenta todos los parámetros necesarios -información requerida, medios de obtención disponibles, características, ubicación, estado y estadística de eficacia de todos y cada uno de ellos, momento límite en que la información o inteligencia es necesaria, etc.-, asignarán automáticamente misiones informativas a aquéllos que el sistema determine como más idóneos, siguiendo permanentemente su cumplimiento. El uso de 


\section{Inteligencia y planificación en el Ejército}

técnicas de inteligencia artificial en estos procesos será de enorme utilidad.

La tecnología del futuro no hará disminuir la importancia de la intervención humana en la obtención de información. El hombre, siempre esencial en todas y cada una de las fases del proceso de inteligencia, es de importancia crítica en este campo. Los agentes contarán con medios técnicos potentes y complejos que facilitarán su labor; la microelectrónica, por ejemplo, pondrá a su disposición micrófonos de tamaño casi microscópico que les permitirá captar señales desde lugar seguro sin riesgo de ser detectados. Los desarrollos en el campo de la electroóptica les permitirán igualmente la observación de detalle de lugares vigilados a gran distancia aunque se hallen en la más completa oscuridad. De igual forma, los avances tecnológicos les permitirán captar conversaciones entre individuos a distancias que les garanticen no ser identificados como agentes. Los avances en la miniaturización de cámaras fotográficas y de vídeo les proporcionarán igualmente significativos incrementos de sus capacidades. Es previsible que se desarrollen incluso nuevas técnicas que aprovechen posibilidades de la mente humana apenas vislumbradas, como la telepatía.

La inteligencia obtenida a partir de imágenes ha sufrido muy ligeros cambios desde la II GM. La disponibilidad de sensores de todo tipo a bordo de satélites ha supuesto fundamentalmente un avance en cuanto al campo cubierto por aquéllos y la posibilidad de obtener información de objetos radiantes de energía a todo lo ancho del espectro. Existen hoy aplicaciones informáticas que permiten al usuario u operador del sistema la «comparación» de dos imágenes mostrando las mismas de forma alternativa para, sobre la base de la retentiva de la retina humana, detectar las diferencias existentes entre aquéllas. Es un proceso lento y prolijo que requiere un gran esfuerzo por parte del operador, por lo que el número de imágenes que puede procesar un individuo en un periodo dado es muy limitado. En el futuro, la aplicación de técnicas informáticas automáticas de correlación de imágenes proporcionará directamente resultados de su comparación casi sin intervención del operador quién, únicamente, deberá refrendar los resultados. Será posible analizar un ingente número de imágenes en un tiempo razonable, con lo que se potenciarán enormemente las capacidades de producir inteligencia a partir de imágenes. La inteligencia obtenida mediante la captación de radiaciones es otra de las ramas en que pueden anticiparse avances espectaculares en un futuro no muy lejano. La posibilidad de traducción simultánea de conversaciones captadas en las 
ondas es uno de esos avances que la tecnología emergente puede facilitar a plazo corto. La correlación automática de «firmas electrónicas» con las referencias disponibles en bases de datos propias asegurará poder disponer de la información necesaria en tiempo oportuno. De igual forma, la utilización de sistemas de sensores basados en satélite permitirá, en forma muy rápida y precisa, el levantamiento del Orden de Batalla electrónico de un potencial adversario.

Utilizados ya en el pasado con éxito por el ejército israelí, los actuales Vehículos Aéreos no Tripulados (UAV) son medios poderosos tanto para inteligencia de señales y de imágenes como en otros campos, según la carga útil de sensores de que vayan dotados. Velocidades supersónicas, sensores miniatura, casi nula firma radar, enlace de datos en tiempo real con las estaciones de control terrestre o controlados desde satélite y otras capacidades conseguidas basándose en tecnologías de última generación, harán de estos elementos armas extraordinariamente útiles como medios de obtención. Como ejemplo de elementos de este tipo que se podrán encontrar en servicio en el futuro valga decir que ya se encuentra muy avanzado el desarrollo de un UAV miniatura, con un peso total de 86 gramos al despegue y una carga útil de 18 gramos, que podrá utilizarse, en lo que a inteligencia se refiere, para colocar diminutos sensores de sonidos y movimientos en determinados puntos del teatro de operaciones o introducirse en áreas donde se sospeche hayan sido empleados agresivos químicos o bacteriológicos.

En otro orden de cosas, avances en la robótica permitirán desarrollar ingenios tipo humanoide, tanto terrestres como aéreos, capaces de transmitir información en tiempo real a puestos de control remotos desde los cuales les serán dadas órdenes de control, tales como cambios de posición o utilización de diferentes sensores dentro de la gama de que estén dotados, etc. Evidentemente, este tipo de máquinas, como los UAV no pertenecen en exclusividad a ninguno de las «ramas» clásicas de inteligencia puesto que pueden obtener información válida para una o más de ellas.

De igual forma que lo expresado para las precedentes «ramas» de inteligencia, es razonable contemplar en el futuro grandes avances en las áreas de Inteligencia Acústica, Inteligencia Técnica etc. La miniaturización de sus componentes permitirá su empleo en el campo estratégico y táctico. Por lo que se refiere a la Inteligencia Técnica, los métodos de correlación permitirán identificar posibles componentes utilizados en desarrollos de armas de destrucción masiva mediante su comparación automática con los datos disponibles en las adecuadas bases de datos. 


\section{Inteligencia y planificación en el Ejército}

Por otra parte, la presente «sociedad de la información» no es más que un anticipo del porvenir. En el futuro, el volumen de información disponible de múltiples fuentes será de tal magnitud que solamente mediante «agentes inteligentes» será posible hacer uso eficaz de la misma. Estos agentes (en realidad, aplicaciones informáticas), en estado muy embrionario en la actualidad debido a su complejidad, existirán por seguro en un horizonte temporal no muy lejano. Mediante ellos, el usuario, conectado a una red de redes especializadas no hará sino definir los elementos de información en los que está interesado; a partir de ese momento, el «agente» realizará tanto una búsqueda permanente de dicha información por toda la red como la selección de la información de interés entre toda la que se reciba.

La comunidad multinacional de inteligencia no es, en el momento actual, insensible al enorme caudal de información que se mueve en la actual red de redes -Internet. Sin embargo, la explotación de esta red con fines de inteligencia presenta profundos problemas de seguridad que habrán de ser resueltos antes de que los analistas especializados puedan estar en condiciones de aprovechar todas las posibilidades que la red ofrece. Los analistas de inteligencia están extrayendo ya gran cantidad de información de fuentes abiertas, que seguirá fluyendo por la Internet del futuro en una sociedad sin barreras.

Se han producido en los últimos años avances muy importantes encaminados a la constitución de una «comunidad internacional de inteligencia» que, en el marco de OTAN, preconiza y persigue el establecimiento de una especie de red exclusiva, especializada y segura que permitirá el acceso, desde el puesto de un analista español por ejemplo, a las bases de datos disponibles en el resto de los países aliados. En este momento, se accede a bastantes de estas bases de datos (la mayoría de ellas de tipo documental) si bien con intervención de un operador; en un futuro no muy lejano dicho acceso será en tiempo real, de forma automática y a todas las bases de datos de cualquier tipo que sean. Si bien este procedimiento no puede considerarse como obtención en su acepción clásica, es evidente el enorme volumen de información que podrá proporcionar a la comunidad de inteligencia.

No quisiéramos concluir este párrafo sin referirnos aunque sea brevemente a los problemas asociados a esa "comunidad de información» en continua expansión: es lo que, en la sociedad anglosajona ha adquirido carta de naturaleza bajo el nombre de «Information Warfare» o Guerra de la Información. Esencialmente y a modo de breve bosquejo de un tema que por su importancia y trascendencia en el futuro bien merecería 
un estudio con detenimiento, la Guerra de la Información se refiere a la batalla que ha de librarse en el futuro (aunque de hecho se haya iniciado ya) por un recurso - la información-cuyo control confiere poder, y cuya pérdida nos deja en inferioridad de condiciones ${ }^{19}$. Varios autores sugieren un futuro en que los medios de comunicación adquirirán una importancia capital, en el que se librarán combates tanto en el campo de batalla como en esos medios de comunicación...... susceptibles tanto de transmitir información como desinformación. Para estos autores, la manipulación de estos medios constituye un elemento esencial de las estrategias de enfrentamiento en el futuro; su control resulta, pues, esencial en la batalla que la comunidad de inteligencia libra. continuamente contra sus potenciales adversarios. Nadie puede ignorar y menos que nadie la comunidad de inteligencia, este problema, con el que, de seguro, nuestra sociedad se va a enfrentar en un futuro que es ya casi presente.

La «elaboración» es muy probablemente la fase del ciclo de inteligencia donde las capacidades tecnológicas actuales han tenido menor influencia debido a las dificultades y complejidad inherentes a la misma. Los sistemas de información de inteligencia existentes en la actualidad han incorporado cierto número de herramientas informáticas que permiten la automatización o semi-automatización de algunas tareas. Los avances tecnológicos facilitarán aún más esas tareas y permitirán acometer otras poco o nada desarrolladas hoy en día. Así, en un futuro a medio plazo, existirán aplicaciones que permitirán llevar a cabo la fusión de datos e información para producir inteligencia en forma automatizada en auxilio del analista. Los desarrollos en técnicas de inteligencia artificial determinarán el momento en que se alcancen unas $\mathrm{u}$ otras de estas capacidades.

Los analistas del futuro podrán trabajar remotamente en forma colectiva en un entorno virtual; es decir, serán capaces, en tiempo real y separados físicamente cientos o miles de kilómetros, de intercambiar puntos de vistas y analizar en forma conjunta un mismo problema. Este procedimiento de trabajo interactivo y en grupo es, conceptualmente, de enorme valor en un campo - la inteligenciadonde la aportación y contraste de diferentes puntos de vista es esencial para obtener un producto de calidad. La tecnología es ya conocida y su implantación y desarrollo pleno y definitivo es una cuestión de tiempo y de eliminación de desconfianzas entre los usuarios De igual forma existirán capacidades técnicas que permitirán a los analistas relacionarse en forma interactiva mediante la voz - digitalizada-, mediante el teclado del ordenador, etc. todo ello a favor del proceso de 


\section{Inteligencia y planificación en el Ejército}

elaboración; es decir, de la transformación de la información en inteligencia.

Proporcionar la inteligencia requerida a aquél que la necesita, y en la forma, momento y lugar que la precisa es la esencia de la fase conocida como «difusión».

Los procedimientos basados en la difusión no selectiva («broadcasting») de los productos elaborados pueden conseguir un efecto contrario al pretendido al llegar a saturar a los usuarios con una información que, muy probablemente, no les sea de utilidad. Por ello, al igual que se decía en el apartado relativo a la obtención, un método factible y muy eficaz para difundir información e inteligencia podrá ser el empleo de «agentes inteligentes» que, a partir de los parámetros definidos para cada uno de los corresponsales, seleccionarán automáticamente lo que sea de interés para cada uno de ellos y se lo transmitirán automáticamente. Un procedimiento de uso continuo será el acceso remoto a bases de datos en las que las diferentes organizaciones pertenecientes a una comunidad nacional y/o internacional de inteligencia pondrán los productos elaborados por ellos a disposición de los demás. Estos accederán a las diferentes bases de datos y extraerán de ellas la información que les sea de interés y sólo la que le sea de interés, en cada momento; con ello, se garantiza la disponibilidad de la información en el momento y en la forma deseada por cada usuario.

En el futuro no habrá que acudir a una multiplicidad de medios para transmitir o intercambiar información. En vez de existir ordenadores y TV, videos, Internet u otros, en el futuro se podrán realizar todas éstas y muchas mas funciones desde un único aparato polivalente que permitirá, con las debidas garantías de seguridad, conectarse directa y remotamente a la red o redes de su interés.

Gran parte de las capacidades hasta aquí descritas descansan en la disponibilidad de unos medios de telecomunicación con unas prestaciones que, en la actualidad empiezan a estar disponibles en los Estados Unidos de América. El carácter global al que la sociedad actual se encamina, hace razonable prever que tales capacidades estarán a disposición de los usuarios en fecha no muy lejana y, con ellas, las de inteligencia que se han descrito.

Como consideración final cabe decir que los Ejércitos, las Fuerzas Armadas, tienen que huir de toda improvisación, anticipando prospectivamente las emergencias a las que puedan tener que afrontarse. El nivel de desarrollo de una Institución compleja como es el Ejército puede medirse no tanto por su capacidad de análisis y reflexión sobre 
el presente como por la atención con que, mediante su planificación estratégica mira hacia el futuro. Uno de los principales contribuyentes a la planificación estratégica es la Inteligencia Militar que, a la postre, ayuda a fijar el porqué, el para qué y en definitiva la necesidad de unas Unidades muy costosas en términos de recursos humanos, materiales y económicos. A ella hemos dedicado fundamentalmente estas reflexiones, de carácter divulgativo e intencionadamente más extensas que profundas, con el deseo de contribuir a despertar un interés, despojado de prejuicios, hacia esta rama primordial de la ciencia militar.

\section{Notas}

1 Ley 17/1999 de 18 de Mayo, de Régimen de Personal de las Fuerzas Armadas.

2 War and Antiwar. Alvin and Heidi Toffler, Warner Books 1993.

3 Directiva de Defensa Nacional 1/96.

4 «New World Desorder». Revista Newsweek, 31 mayo 1999.

5 Del mantenimiento del orden a las guerras de alta tecnología. Maurice Najman, Le Monde Diplomatique Febrero 1998.

6 Notas del analista de inteligencia; R.H. Mathams, Centro de Estudios de Estrategia y Defensa, Universidad Nacional de Australia.

7 R.H. MATHAMS, trabajo citado.

8 Análisis factorial de las causas que originan conflictos bélicos. Cuaderno de Estrategia 69 CESEDEN.

9 Intelligence: A consumer's guide. John MACARTNEY, International Journal of Intelligence and Counterintelligence, Vol. $2 \mathrm{n}^{\circ} 4$ (1989).

10 R.H. MATHAMS, trabajo citado.

11 Ricardo TorRon DURÁN, General de División Dr. Ingeniero de Armamento. «El Análisis de Sistemas", monografía No 16 de ISDEFE, marzo 1997

12 Este epígrafe se basa en el método descrito en la publicación Assumption -Based Planning. Publicada en 1993 por RAND Corporation para el Ejército de los EE.UU.

13 Shlomo GazIT. Estimates and Fortune Telling. Revista International Security, Vol. $4 \mathrm{n}^{\circ} 4$ - Primavera 1980.

14 SAATY T. \& BOONE L. (1990). Embracing the Future: Meeting the Challenge of our Changing World. Praeger, New York.

15 Trudi Lang. An Overview of Four Future Methodologies.

16 Ricardo TORRÓN DURÁN. Obra citada.

17 El autor agradece la colaboración y aportación de ideas del Coronel de Artillería, DEM. Valentín Martinez Valero, experto en Sistemas de Información para Inteligencia.

18 La publicación STAR 21 - Strategic Technologies for the Army of the Twenty First Century, National Academy Press, Washington D.C. 1992 proporciona una visión tecnológica prospectiva referida, entre otros, a los medios de Inteligencia.

19 Alvin and Heidi TOFFler, obra citada. 